Table 1

Mean Number of "Left Larger" Reports as a Function of Areal Ratio

\begin{tabular}{l|c|c|c|c|c}
\hline & \multicolumn{5}{|c}{ Areal Ratio } \\
\hline Group & $1.29: 1$ & $1.11: 1$ & $1: 1$ & $1: 1.11$ & $1: 1.29$ \\
\hline $\mathrm{D}$ & 3.67 & 3.40 & 1.80 & 0.60 & 0.20 \\
$\mathrm{~S}$ & 3.27 & $3.4 \mathrm{C}$ & 1.47 & 0.60 & 0.33 \\
$\mathrm{~N}$ & 4.00 & 3.73 & 1.67 & 0.33 & 0.13 \\
\hline
\end{tabular}

Table 2

Mean Number of "Left Farther" Reports as a Function of Areal Ratio

\begin{tabular}{l|c|c|c|c|c}
\hline & \multicolumn{5}{|c}{ Areal Ratio } \\
\cline { 2 - 6 } Group & $1.29: 1$ & $1.11: 1$ & $1: 1$ & $1: 1.11$ & $1: 1.29$ \\
\hline $\mathrm{D}$ & 1.40 & 1.27 & 2.13 & 2.74 & 2.33 \\
$\mathrm{~S}$ & 1.40 & 1.80 & 1.67 & 1.73 & 2.07 \\
$\mathrm{~N}$ & 1.20 & 1.53 & 1.93 & 2.27 & 2.33 \\
\hline
\end{tabular}

viewed objects presented in a series of preliminary slides.

\section{RESULTS}

The response measures of interest were the number of "left larger" and "left farther" reports at each relative size (areal ratio) level. The maximum possible value at each level was 4.0. Table 1 shows the mean number of "left larger" reports at each of the five areal ratios for each instruction condition. As expected, there was a marked tendency toward veridicality of relative size judgments; the number of "left larger" judgments was greater when the left image was, in fact, larger than when the right image was larger, $F(4,168)=263.44$, $\mathrm{p}<.001$. However, there was no effect of instructional condition, $F(2,42)=1.31$, $\mathrm{p}>.05$, and there was no interaction, $F(8,168)=1.56, p>.05$.

Table 2 indicates a general trend, $F(4,168)=6.61, p<.01$, for $S$ s to report the larger image as being nearer. Thus, when the left image was larger it was reported as being the farther of the twoless often than when the right image was larger. The effect of instructional condition was not statistically reliable, $F(2,42)=0.81$, $\mathrm{p}>.05$, nor was the interaction between instruction condition and areal ratio reliable, $F(4,168)=1.10, p>.05$.

An additional analysis was performed on these data. Since the apparently larger image was expected to be judged as nearer, $\mathrm{Ss}$ ' reports of the larger and the farther images should have been different, e.g., if the left image was judged as larger, the right image should have been judged as farther. Indeed, the number of these "different" judgments was greater than the number of judgments of the same image as both larger and farther, $F(1,168)=10.64$, $\mathrm{p}<.01$. Group differences were not significant, $\mathrm{p}>.05$.

\section{DISCUSSION}

The image subtending the larger visual angle was expected to be judged as the closer image when the two were assumed to be of equal actual size but not when they were assumed to be differently sized. Differences in visual extent, under such conditions, are assumed to result from distance differences. The results do not support this proposition, since judgments of relative size were unaffected by instructions designed to influence these judgments. Had the instructions served their intended purpose, a significant Group by Areal Ratio interaction would have been expected; $S$ s in Group $S$ and possibly Group N should have made more nearly equal numbers of "left larger" and "right larger" reports at all areal ratios than $\mathrm{Ss}$ in Group D. However, despite the absence of group differences in relative size judgments, variations in areal ratio affected judgments of relative distance of all three groups in a statistically equal manner: Ss tended to report the objectively larger figure as nearer, regardless of instructions concerning relative size.

The data, particularly those of Group D, do not, of course, conflict with the size-distance invariance hypothesis; they are, at best, merely suggestive. A test of the applicability of this hypothesis with stimuli generated by the random stereogram technique will require the measurement of perceived size and distance, rather than paired-comparison measurements of relative size and distance. Work is presently in progress on the development of a version of Gregory's (1965) range-finder technique, which should make possible the measurement of perceived stereoscopic depth.

\section{REFERENCES}

AYES, A. JR Some demonstrations concemed with the origin and nature of sensations: $A$ lab manual. Hanover, N.H: Dartmouth Eye Institute, 1946.

CARLSON, V. R. Overestimation in size-constancy judgments. American Journal of Psychology, 1960, 73, 199-213.

EPSTEIN, W. Varieties of perceptual learning. New York: McGraw-Hill. 1967.

GREGORY, R. L. Seeing in depth. Nature, 1965 , 207, 16-17.

ITTELSON, W. H. Visual space perception New York: Springer, 1960.

KAUFMAN, L. Suppression and fusion in viewing complex stereograms. American Journal of Psychology, 1964a, 77, 193-205.

KALFMAN, L. On the nature of binocular disparity. American Joumal of Psychology, $1964 b, 77,393-402$.

KAUFMAN, L. Some new stereoscopic phenomena and their implications for a theory of stereopsis. American Journal of Psychology, $1965,78,1-20$.

TOLIN, P. Size-distance judgments with random letter stereograms. Perception \& Psychophysics, 1969, 6, 340-342.

\title{
The portable rod-and-frame test and the short-form embedded-figures test: A combined index of the field-dependence dimension*
}

\author{
STEVEN JAY GROSS and SAMUEL. F. MOORE \\ University of Cincinnati, Cincinnati, Ohio 45221
}

The utilization of the portable rod-and-frame test and the short-form embedded-figures test as a combination index of the field-dependence/independence dimension that takes no longer in administration time than a single standard test was explored. Both normative data and the relationship between these instruments are presented. Marked scatter for the field-dependent Ss on these two measures was found. An alternative strategy for selecting Ss and difficulties with that alternative is discussed.

Since Witkin and his associates (1954, 1962,1965 ) introduced the field-dependence/independence dimension, there have been numerous studies investigating perception-personality relationships. Discrepancies in results for such studies (Immergluck, 1968; Pressey \& Koffman, 1968) have led a number of investigators (Lester, 1968; Neville, Workman, \& Johnson, 1969; Pressev.

*Our thanks to Dr. Richard Melton for his suggestions and aid in the preparation of this paper.
1968; Vaught, 1968, 1970) to hypothesize that different administration procedures for the independent measures and/or different S-selection criteria might account for these discrepancies. A review of these studies, however, reveals that most often only a single instrument was used for measuring the field-dependence/ independence dimension (e.g., Immergluck, 1968). This suggests an alternate hypothesis to account for the aforementioned differing results, namely, that the construct field 


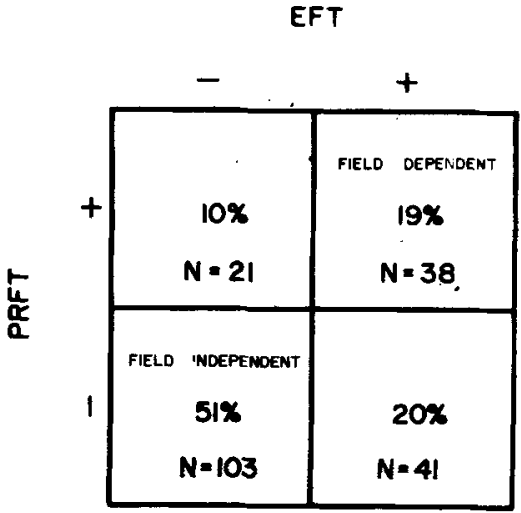

Fig. 1. Percentage of Ss above and below the mean on PRFT and short-form EFT.

dependence-independence may not be validly specified by a single instrument.

The major instruments used to assess field dependence-independence have been the Rod-and-Frame Test (RFT) and the Embedded-Figures Test (EFT). These instruments have rarely been used in combination because of pragmatic considerations, with length of administration time being primary among these. Such practical difficulties have resulted in the introduction of a modified, portable rod-and-frame test (PRFT) (Oltman, 1968) and a short-form embedded figures test (Jackson, 1956).

The short-form EFT markedly reduces the long time some Ss need to complete the test, as well as providing a good approximation of the results obtained from the standard EFT (correlating .96 for both men and women). The PRFT also reduces administration time. More importantly, however, it has eliminated the need for a dark room, thereby permitting research workers greater flexibility in the number of locations in which Ss can be tested, while still providing a reasonably valid index of the field-dependence/independence dimension (correlating .89 men and .90 women with the standard RFT). In the light of these practical advantages of both the PRFT and the short-form EFT, it is likely that both instruments will be used extensively, either independently or in combination.

The present study is an attempt, first, to provide normative data on the use of the PRFT and the short-form EFT within a male, college population; second, to investigate the relationship between these two instruments; and third, to examine the utility of a combined index as a criterion for $S$ selection along the field-dependence/independence dimension. METHOD

The Ss were 203 male volunteers enrolled at the University of Cincinnati.
The PRFT and the short-form EFT (3-min time limit per card) were individually administered. Administration procedures followed those outlined by Oltman (1968) and Jackson (1956). Additional control was achieved by administering the PRFT in a dark room in which light intensity was under the control of $E$, insuring an equal intensity of light across experimental trials for all Ss. A shadow-free distribution of light within the apparatus was achieved by draping the room with black cloth. Ambient white noise (produced by amplifying the sound of air exhausted from a hair dryer) was used to mask distracting sounds.

\section{RESULTS}

The means were 26.18 for the PRFT and 530.54 for the short-form EFT; the standard deviations were 22.27 and 335.50 , respectively. Both the shape of the distribution (moderate positive skew) and range of scores are compatible with other findings, though the PRFT mean and standard deviation are somewhat lower than the respective 45.80 and 36.90 reported by Oltman (1968). The PRFT and the short-form EFT correlated .45 $(p<.01)$. The time for the administration of the PRFT ranged from 8 to $12 \mathrm{~min}$, and from 10 to $50 \mathrm{~min}$ for the short-form EFT.

The PRFT and short-form EFT scores were converted to standard deviation units for the purpose of computing combined index scores. These scores were plotted in a scatter diagram. Since the distributions exhibited moderate positive skew, the expected preponderance of Ss was found in the field-independent quadrant (Table 1). Furthermore, the field-independent quadrant (Ss who scored in a field-independent direction on both measures) revealed a tight clustering of points. This pattern was in contrast to that of the field-dependent quadrant where there was marked spread among the points.

PRFT scores were grouped according to their respective EFT intervals ( .3 standard deviation units). The mean PRFT and their associated ranges were plotted. Both the means and their ranges increased linearly according to the EFT intervals. That is, field-dependent PRFT means tended to have larger ranges than did field-independent PRFT means.

\section{DISCUSSION}

The present investigation was an attempt to study the utility of a combined index score for assessing the field-dependence/independence dimension. A combination of measures that takes no longer in administration than a single standard instrument provides the advantage of a multimethod assessment $i$ the field-dependence/independence construct. The use of this combined index, however, requires caution as the obtained correlation (.45) accounts for only $20 \%$ of the variance. In addition, $30 \%$ of the individuals scoring in one direction on one measure scored in the opposite direction on the other (see Table 1). The high degree of scatter in the field-dependent quadrant indicates that the prediction of performance is particulary poor for these Ss. This would seem to violate Witkin's (1962) assumption that the field-dependence/independence dimension is a pervasive characteristic of an individual's performance on a variety of tasks. One alternative to resolve this dilemma might be to require that Ss score one standard deviation above or below the mean on at least two measures. The adoption of such a stringent criterion, however, might call into question the utility of the field-dependencel independence dimension, particulary within a homogeneous population such as the one in the present study. More importantly, the obtained distribution for the short-form EFT suggests that it is a more useful measure than the portable RFT for assessing the field-dependence/ independence dimension within a male college population.

\section{REFERENCES}

IMMERGLUCK, L. Comment on "Figural aftereffects, illusions and the dimension of field dependence." Psychonomic Science, $1968,11,363$.

JACKSON, D. N. A short form of Witkin's Embedded-Figures Test. Journal of Abnormal \& Social Psychology, 1956, 53, 254-255.

LESTER, G. The Rod-and-Frame Test: Some comments on methodology. Perceptual \& Motor Skills, 1968, 26, 1307-1314.

NEVILLE, C., WORKMAN, S., \& JOHNSON, D. Expected scores in the Rod-and-Frame Test: Field dependence is where you find it. Psychonomic Science, 1969, 15, 321-322.

OLTMAN, P. K. A portable rod-and-frame apparatus. Perceptual \& Motor Skills, 1968 26, 503-506.

PRESSEY, A. A reply to comments of "Figural aftereffects, illusions and the dimension of field dependence." Psychonomic Science, $1968,11,364$.

PRESSEY, A., \& KOFFMAN, G. Figural aftereffects, illusions and the dimension of field dependence. Psychonomic Science, 1968 . $10,279-280$.

VAUGHT, G. Expected scores in the rod-and-frame test: Fuel for the Immergluck-Pressey fire. Psychonomic Science, 1968, 13, 248.

VAUGHT, G. Expected scores. in the rod-and-frame test revisited. -Psychonomic Science, 1970, 18, 111.

WITKIN, H. A., LEWIS, H. B., HERTZMAN, M., MACHOVER, K., MEISSNER, P. B., \& WAGNER, S. Personality through perception. New York: Harper, 1954

WITKIN, H. A., DYK, R. B., FATERSON, H. F., GOODENOUGH, D. R, \& KARP, S. A. Psychological differentiation: Studies of development. New York: Wiley, 1962.

WITKIN, H. A. Psychological differentiation and form of pathology. Journal of Abnormal Psychology, 1965, 70, 317-336. 